\title{
Nasopharyngeal Salivary Gland Anlage Tumour A rare cause of neonatal respiratory distress
}

"Salma M. Al-Sheibani, ${ }^{1}$ Kiran P. Sawardekar, ${ }^{2}$ Salwa J. Habib, ${ }^{3}$ Hunaina M. Al-Kindi ${ }^{4}$

$$
\text { ورم الغدة اللعابية الأنفبلعومية البدائي }
$$

سالمة محمد الشيباني، كيران صوارديكار، سلوى جعفر حبيب، حنينه محمد الكندي

ABSTRACT: A salivary gland anlage tumour (SGAT) is a very rare type of benign tumour that usually presents in early infancy with respiratory distress which is exacerbated upon feeding. We report a full-term male neonate who was referred to the Al Nahdha Hospital, Muscat, Oman, in 2015 with severe neonatal respiratory distress due to a nasopharyngeal obstruction immediately after birth. Computed tomography and magnetic resonance imaging revealed a well-circumscribed mass in the nasopharynx, without intracranial extension. Histopathological analysis of the lesion confirmed a diagnosis of SGAT. Following excision of the tumour, the postoperative period was uneventful. No recurrence was observed over the next two years. This case report highlights the importance of the early recognition of this extremely rare and potentially life-threatening, yet easily curable, condition.

Keywords: Nasopharyngeal Neoplasms; Salivary Gland Neoplasms; Neonatal Respiratory Distress Syndrome; Case Report; Oman.

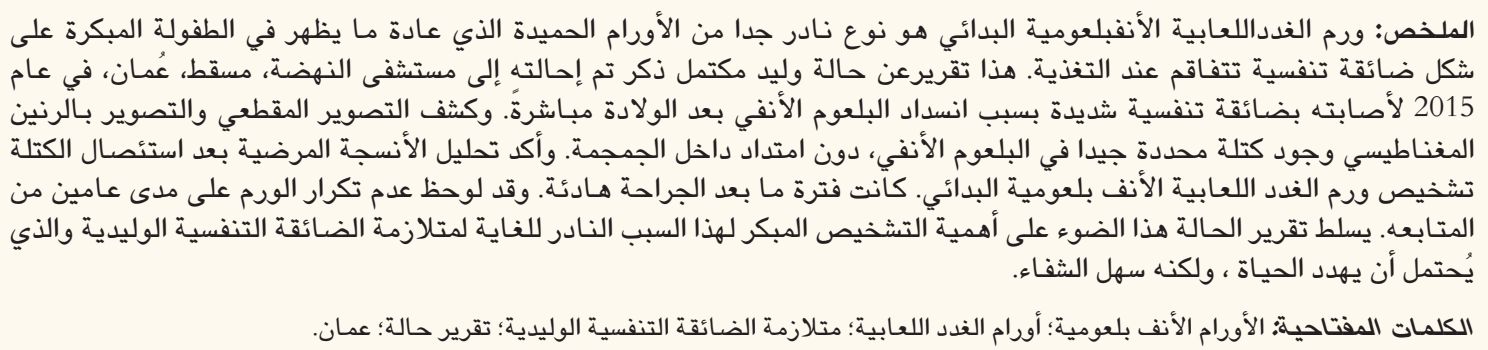

A S HUMAN INFANTS ARE OBLIGATE NASAL breathers, any nasal or nasopharyngeal obstruction during early infancy can be life-threatening. Such obstructions may be due to congenital malformations, inflammatory conditions, infectious diseases or neoplastic or hamartomatous entities. ${ }^{1}$ Neonates may present with symptoms of nasal discharge, feeding and sleeping difficulties, cyanosis, noisy breathing, respiratory distress or sudden choking. ${ }^{1,2}$ A salivary gland anlage tumour (SGAT) is a very rare benign lesion which usually presents in early infancy with respiratory distress and feeding difficulties. ${ }^{2,3}$ Other symptoms include facial plethora, intermittent apnoea, nasal discharge and epistaxis, which can occur even after gentle nasal manipulation. Rarely, coughing and sudden choking may occur due to the dislodgement of the mass; this is sometimes followed by the expulsion of the mass, thus relieving the breathing difficulties. ${ }^{2,3}$
According to the 2017 World Health Organization classification of head and neck tumours, SGAT is one of the three types of epithelial tumour unique to the nasopharynx. ${ }^{4}$ To date, more than 30 cases of SGAT have been reported in the literature..$^{2,3,5-10}$ To the best of the authors' knowledge, this is the first reported case of neonatal SGAT from Oman.

\section{Case Report}

A full-term male neonate was born at a district hospital in Al-Dakhiliyah Governorate, Oman, in 2015 by vacuum-assisted vaginal delivery. There was no history of antenatal problems or polyhydramnios. The Apgar scores at one and five minutes were 7 and 9, respectively. Immediately after birth, the neonate developed severe respiratory distress, at which point he was referred to the Neonatal Intensive Care Unit of Nizwa Hospital, Nizwa, Oman. He maintained a 


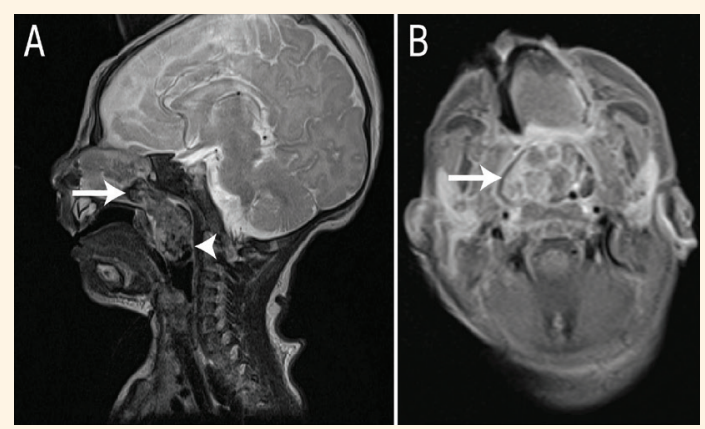

Figure 1: Magnetic resonance imaging of the nasopharynx of a full-term male neonate. A: Sagittal T2weighted image showing an iso-to-hypointense mass occupying the entire nasopharynx (arrow) and extending to the nasal cavity (arrowhead). B: Post-contrast axial T1-weighted image showing a well-demarcated mildlyenhancing heterogeneous mass occupying the entire nasopharynx (arrow).

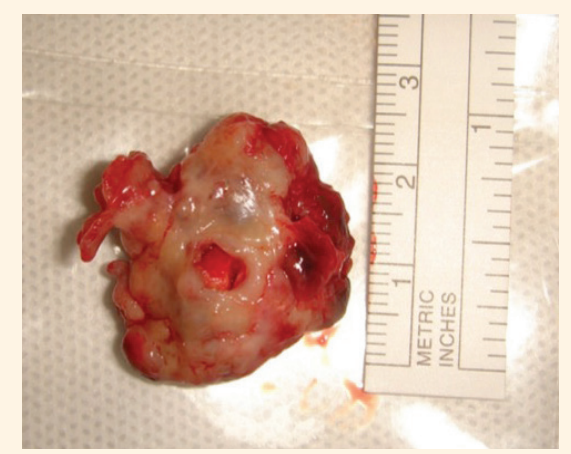

Figure 2: Gross photograph of the excised mass.

peripheral blood oxygen saturation of $90 \%$ with $3 \mathrm{~L}$ of oxygen delivered via nasal catheter. A detailed head and neck assessment did not reveal any abnormalities or features of a craniofacial syndrome and there was no evidence of stridor.

Anterior rhinoscopy did not reveal any abnormalities. A suction catheter (size 8FG) could be inserted through the left choana; however, attempts to insert the catheter through the right nasal aperture resulted in epistaxis and progressive respiratory distress requiring intubation and ventilation. Subsequently, the patient was referred for further evaluation to the Al Nahdha Hospital in Muscat, Oman. Fibreoptic nasopharyngoscopy revealed a large nasopharyngeal mass completely occluding the right choana, while the left one was patent. Contrast computed tomography (CT) of the nasopharynx revealed a heterogeneous midline nasopharyngeal mass measuring 37 x 25 x $32 \mathrm{~mm}$. It extended into the right nasal cavity through the right choana, without any signs of bony destruction. Magnetic resonance imaging (MRI) showed a welldefined lobulated heterogeneous mass occupying the entire nasopharynx and extending into the right nasal cavity. There was no intracranial or parapharyngeal

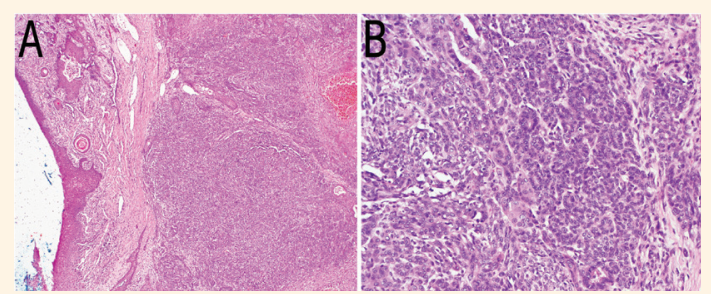

Figure 3: Haematoxylin and eosin stains at (A) x100 magnification showing a non-keratinising squamous mucosa and (B) at x200 magnification showing an admixture of epithelial groups of duct-like structures and rounded ovoid-to-spindle-shaped cells.
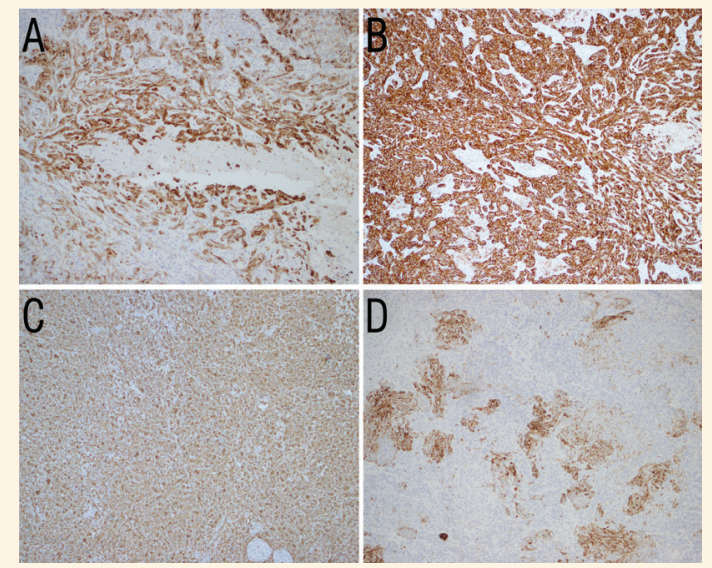

Figure 4: Immunohistochemistry panel at x200 magnification showing positivity for (A) epithelial membrane antigen, (B) cytokeratin AE1/AE3, (C) protein 63 and (D) focal glial fibrillary acidic protein.

space extension. In comparison to the brain parenchyma, the mass was iso-to-hypointense on T2weighted and mildly hyperintense on T1-weighted images [Figure 1].

An endoscopic assessment confirmed that a firm mass attached to the posterior edge of the nasal septum was completely blocking the right choana and nasopharynx. The mass was completely excised and extracted via the oral cavity. A ruptured blood vessel at the posterior edge of the septum was cauterised. The excised mass was $2.5 \times 3.5 \mathrm{~cm}$ in size with a smooth nodular surface [Figure 2]. A histological examination of the mass confirmed microscopic features of SGAT [Figures 3 and 4]. Overall, the outcome of the excision was excellent. The postoperative period was uneventful and there were no signs of recurrence at a two-year follow-up appointment.

\section{Discussion}

In 1979, Stillwater et al. reported a newborn with a squamous cell proliferative lesion of the nasopharynx. ${ }^{11}$ Subsequently, Har-El et al. described a case of congenital pleomorphic adenoma in $1985 .{ }^{12}$ 
Both of these entities bore striking histological similarities to SGAT. ${ }^{11,12}$ Dehner et al. first coined the current terminology in their description of nine infants with SGAT. ${ }^{13}$ In eight cases, a simple excision of the mass was performed; however, in one case, the mass was spontaneously expelled from the mouth as a result of resuscitative efforts after the infant had gone into respiratory arrest. In all cases, the mucosal surface of the tumour showed features of a budding non-keratinised squamous epithelium with focal ulcerations and a central compact multinodular mesenchyme. ${ }^{13}$ The submucosal zone consisted of cylindrical branching duct-like structures with nests of squamous cells and cysts within a hypocellular stroma of varying thickness. It was continuous with the surface epithelium and extended into the septal zones of the mesenchyme. ${ }^{13}$ The mesenchyme consisted of densely cellular fascicles of ovoid-to-spindle-shaped cells, with smooth muscle histological and histochemical features; these constituted $50-75 \%$ of the entire volume of the mass. ${ }^{13}$

Based on its histological features, Dehner et al. claimed that SGAT resembles the phase of salivary gland development in which the embryonic ectoderm/ endoderm proliferates into the underling mesenchyme. ${ }^{13}$ The lesion arises from the nasopharyngeal midline and is tethered by a short thin friable pedicle to either the posterior aspect of the nasal septum, the palate or the nasopharyngeal wall. ${ }^{13-15}$ In the current case, it was attached to the posterior edge of the septum.

Overall, SGAT has a strong male preponderance. ${ }^{2,5,7,13}$ Boccon-Gibod et al. reported a male neonate with SGAT in whom the pedunculated mass protruded into the upper part of the oesophagus, completely obstructing both choanae, with a sharp border between the base of the skull and the mass on MRI imaging. ${ }^{14}$ Bondeson et al. reported a newborn boy with SGAT. ${ }^{15}$ A clinical examination indicated the presence of a polypoid mass which filled the nasopharynx and protruded one $\mathrm{cm}$ below the soft palate. Subsequently, a transpalatal exploration procedure with division of the soft palate revealed that the lesion was attached to the posterior edge of the nasal septum by a thin pedicle. ${ }^{15}$ The tumour was removed without difficulty. ${ }^{15}$

Radhakrishnan et al. reported a case of SGAT secondary to polyhydramnios which was detected in utero via fetal MRI; a postnatal CT scan confirmed the diagnosis and the lesion was resected when the infant was four days old. ${ }^{9}$ Martin et al. reported a case of SGAT in a two-week-old female infant presenting with meningitis. ${ }^{10} \mathrm{~A} \mathrm{CT}$ scan revealed a homogeneously-enhancing mass within the left nasal cavity, extending through the cribriform plate into the anterior cranial fossa. An MRI confirmed the intracranial extension of the mass into the olfactory recess. ${ }^{10}$ Vranic et al. reported a case of SGAT in a 12-month-old infant who presented with intermittent airway obstruction and otitis media with bilateral middle ear effusion. ${ }^{8}$ Cytogenetic analysis did not reveal trisomy 12 and $1 p$ deletion-as observed in cases of sinonasal teratocarcinosarcoma-as such, the authors concluded that SGAT is a hamartoma rather than a neoplasm. ${ }^{8}$ This hypothesis is also supported by the midline location, limited growth potential and immunohistopathological features of SGAT which resemble those of the embryonic salivary glands. ${ }^{\text {? }}$

The evaluation of neonatal nasal obstruction requires a comprehensive systematic approach. ${ }^{1} \mathrm{~A}$ maternal history should include the medications used during pregnancy and any screening for infectious diseases, especially chlamydia, gonorrhoea and syphilis. A comprehensive family history of congenital, developmental or syndromic abnormalities should also be obtained. The birth history may also indicate potential causes of iatrogenic nasal obstruction. ${ }^{1}$ Finally, the physical examination should include an evaluation of associated congenital syndromes that may warrant consultation with a geneticist. Anterior rhinoscopy may reveal a deviated septum due to birth trauma, nasal pyriform aperture stenosis, mucosanguinous rhinorrhoea with thick or bloody nasal discharge indicative of congenital syphilis or chlamydia, but very rarely a nasal mass. Cohen et al. suggested that it might be prudent for physicians to place their index finger in the oropharynx when inserting a flexible catheter so as to evaluate choanal patency, rule out choanal atresia and identify and dislodge foreign bodies or masses before they cause an unexpected life-threatening obstruction. ${ }^{2}$

Congenital midline masses such as dermoid cysts, nasal gliomas and encephaloceles may have intracranial extension; hence, a biopsy should not be performed before imaging. ${ }^{1}$ Lymphovascular malformations tend to occur more commonly in other head and neck regions in comparison to the nasal cavity. ${ }^{5}$ Malignant neoplasms such as rhabdomyosarcomas, neuroblastomas, chloromas, lymphomas and Langerhans cell histiocytosis are extremely rare in neonates and are more commonly seen in older infants and children. ${ }^{6}$ A fibre optic examination can help in visualising these lesions in the posterior choanae and nasopharynx.

Contrast CT and/or MRI scans are invaluable in delineating the size of a nasopharyngeal mass and defining its characteristics and relationship to surrounding structures. ${ }^{9}$ In the present case, the 
midline location of the mass and the absence of calcium, fat or fluid signal components were strongly suggestive of SGAT. A nasopharyngeal teratoma was ruled out due to the lack of distortion of the osseous structures of the skull base or intracranial extension; moreover, there were no foci of high-signal intensity on the T1-weighted images. ${ }^{9}$ A dermoid was also excluded from the differential diagnosis as there was no relation between the mass and the lateral nasal wall or turbinates and no high-signal intensities on the T1weighted images indicative of fat. Most cases of SGAT have an excellent outcome, with no cases of recurrence after excision reported to date..$^{7,14}$

\section{Conclusion}

SGAT is a very rare but treatable cause of neonatal respiratory distress. Simple excision of the lesion results in an excellent outcome for the patient, with no recurrence reported to date. This entity should be considered in the differential diagnosis of a nasopharyngeal mass presenting in the neonatal period.

\section{References}

1. Gnagi SH, Schraff SA. Nasal obstruction in newborns. Pediatr Clin North Am 2013; 60:903-22. doi: 10.1016/j.pcl.2013.04.007.

2. Cohen EG, Yoder M, Thomas RM, Salerno D, Isaacson G. Congenital salivary gland anlage tumor of the nasopharynx. Pediatrics 2003; 112:e66-9.

3. Swayampakula AK, Ischander M, Zuppan CW, Krishnan M, Tong K, Qureshi S. Newborn with congenital salivary gland anlage tumor presenting with respiratory distress. Int J Pediatr Otorhinolaryngol Extra 2015; 10:42-4. doi: 10.1016/j.pedex.20 15.03.003

4. Stelow EB, Wenig BM. Update from the 4th edition of the World Health Organization classification of head and neck tumours: Nasopharynx. Head Neck Pathol 2017; 11:16-22. doi: 10.1007/s12105-017-0787-0.
5. Tinsa F, Boussetta K, Bousnina S, Menif K, Nouira F, Haouet S et al. Congenital salivary gland anlage tumor of the nasopharynx. Fetal Pediatr Pathol 2010; 29:323-9. doi: 10.3109/15 513811003796961

6. Mogensen MA, Lin AC, Chang KW, Berry GJ, Barnes PD, Fischbein NJ. Salivary gland anlage tumor in a neonate presenting with respiratory distress: Radiographic and pathologic correlation. AJNR Am J Neuroradiol 2009; 30:1022-3. doi: 10.31 74/ajnr.A1364

7. Gauchotte G, Coffinet L, Schmitt E, Bressenot A, Hennequin V, Champigneulle J, et al. Salivary gland anlage tumor: A clinicopathological study of two cases. Fetal Pediatr Pathol 2011; 30:116-23. doi: 10.3109/15513815.2010.524690.

8. Vranic S, Caughron SK, Djuricic S, Bilalovic N, Zaman S, Suljevic I, et al. Hamartomas, teratomas and teratocarcinosarcomas of the head and neck: Report of 3 new cases with clinico-pathologic correlation, cytogenetic analysis, and review of the literature. BMC Ear Nose Throat Disord 2008; 8:8. doi: $10.1186 / 1472-6815-8-8$.

9. Radhakrishnan R, Calvo-Garcia MA, Lim FY, Elluru RG, Koch BL. Congenital salivary gland anlage tumor: In utero and postnatal imaging. Pediatr Radiol 2015; 45:453-6. doi: 10.1007/s00247014-3113-y.

10. Martin JE, Tessema B, Beshai B, Balarezo F. Congenital salivary gland anlage tumor: An unusual anterior skull base mass in the neonatal period. Pediatr Neurosurg 2017; 52:185-8. doi: 10.11 $59 / 000464296$

11. Stillwater LB, Fee WE Jr. Squamous cell proliferative lesion of the nasopharynx in a newborn. Otolaryngol Head Neck Surg (1979) 1980; 88:240-7. doi: 10.1177/019459988008800310.

12. Har-El G, Zirkin HY, Tovi F, Sidi J. Congenital pleomorphic adenoma of the nasopharynx (report of a case). J Laryngol Otol 1985; 99:1281-7. doi: 10.1017/S0022215100098546.

13. Dehner LP, Valbuena L, Perez-Atayde A, Reddick RL, Askin FB, Rosai J. Salivary gland anlage tumor ("congenital pleomorphic adenoma"): A clinicopathologic, immunohistochemical and ultrastructural study of nine cases. Am J Surg Pathol 1994; 18:25-36. doi: 10.1097/00000478-199401000-00003.

14. Boccon-Gibod LA, Grangeponte MC, Boucheron S, Josset PP, Roger G, Berthier-Falissard ML. Salivary gland anlage tumor of the nasopharynx: A clinicopathologic and immunohistochemical study of three cases. Pediatr Pathol Lab Med 1996; 16:973-83. doi: 10.1080/15513819609168721.

15. Bondeson L, Andreasson L, Olsson M, Rausing A. Salivary gland anlage tumor: Cytologic features in a case examined by fine-needle aspiration. Diagn Cytopathol 1997; 16:518-21. doi:10.1002/(SICI)1097-0339(199706)16:6<518::AID-DC9>3.0. $\mathrm{CO} ; 2-5$. 